\section{JURNAL EKONOMI EFEKTIF}

ISSN : $2622-8882$, E-ISSN : 2622-9935

Jurnal Ekonomi Efektif, Vol. 3, No. 2, Januari 2021 @Prodi Manajemen Fakultas Ekonomi Universitas Pamulang

\title{
PENGARUH CITRA MEREK TERHADAP KEPUTUSAN PEMBELIAN SEPATU WATCHOUT DI GIANT DEPT STORE BINTARO
}

\author{
Mohammad Amas Lahat ${ }^{1 *}$, Rosento Sento ${ }^{2}$, Amas Sari Marthanti ${ }^{3}$ \\ Universitas Bina Sarana Informatika, Jakarta, Indonesia \\ m.amas.mas@bsi.ac.id*
}

Manuskrip: Sept-2020; Ditinjau: Okt-2020; Diterima: Okt-2020; Online: Jan-2021; Diterbitkan: Jan-2021

\begin{abstract}
ABSTRAK
Penelitian ini bertujuan untuk mengetahui pengaruh citra merek terhadap keputusan pembelian sepatu Watchout di Giant Dept Store Bintaro. Metode yang digunakan adalah explanatory research dengan sampel sebanyak 96 responden. Teknik analisis menggunakan analisis statistik dengan pengujian regresi, korelasi, determinasi dan uji hipotesis. Hasil penelitian ini variabel citra merek diperoleh nilai rata-rata skor sebesar 3,401 dengan kriteria baik. Variabel keputusan pembelian diperoleh nilai rata-rata skor sebesar 3,829 dengan kriteria baik. Citra merek berpengaruh positif dan signifikan terhadap keputusan pembelian dengan nilai persamaan regresi $\mathrm{Y}=8,943+0,863 \mathrm{X}$, dan nilai koefisien korelasi 0,783 atau memiliki tingkat hubungan yang kuat dengan nilai determinasi $61,4 \%$. Uji hipotesis diperoleh signifikansi $0,000<0,05$.
\end{abstract}

Kata Kunci: Citra Merek, Keputusan Pembelian.

\begin{abstract}
This study aims to determine the effect of brand image on purchasing decisions Watchout shoes at the Giant Dept Store Bintaro. The method used is explanatory research with a sample of 96 respondents. The analysis technique uses statistical analysis with regression testing, correlation, determination and hypothesis testing. The results of this study, the brand image variable obtained an average score of 3.401 with good criteria. The purchase decision variable obtained an average score of 3.829 with good criteria. Brand image has a positive and significant effect on purchasing decisions with a regression equation value of $Y=8.943+$ $0.863 X$, and a correlation coefficient value of 0.783 or has a strong level of relationship with a determination value of 61.4\%. Hypothesis testing obtained a significance of $0.000<0.05$.
\end{abstract}

Keywords: Brand Image, Purchase Decision. 


\section{PENDAHULUAN}

\section{A. Latar Belakang Masalah}

Syarat yang harus dipenuhi oleh suatu perusahaan agar dapat mencapai sukses dalam persaingan adalah berusaha mencapai tujuan untuk menciptakan dan mempertahankan pelanggan. Agar tujuan tersebut tercapai, maka setiap perusahaan harus berupaya menghasilkan dan menyampaikan barang dan jasa yang diinginkan konsumen. Dengan demikian setiap perusahaan harus mampu memahami perilaku konsumen pada pasar sasarannya, karena kelangsungan hidup perusahaan tersebut sebagai organisasi yang berusaha memenuhi kebutuhan dan keinginan para konsumen sangat tergantung pada perilaku konsumennya.

Suatu perusahaan harus bekerja keras membuat kebijakan-kebijakan strategis baru dalam menjual produk dan jasa mereka dalam kaitannya menghadapi persaingan yang ketat dengan competitor yang dapat memberikan value yang lebih besar kepada pelanggan. Pada dasarnya dengan semakin banyaknya pesaing maka semakin banyak pula pilihan bagi pelanggan untuk dapat memilih produk yang sesuai dengan apa yang menjadi harapannya. Sehingga konsekuensi dari perubahan tersebut adalah pelanggan menjadi cermat dan pintar dalam menghadapi setiap produk yang diluncurkan di pasar.

Dalam perkembangan selanjutnya, maka konsumen menjadi faktor kunci menjadi penentu atas keberhasilan atau kegagalan suatu perusahaan didalam memasarkan produknya. Perusahaan harus mampu mengenali secara dini apa yang menjadi kebutuhan dan harapan konsumen saat ini maupun masa yang akan datang. Seorang manajer pemasaran harus mampu mempunyai pengetahuan yang seksama tentang perilaku konsumen agar dapat memberikan defisini pasar yang baik untuk mengikuti perubahan yang terus-menerus, serta untuk merancang bauran pemasaran yang tepat.

Di era globalisasi, menjanjikan suatu pelanggan dan tantangan bisnis baru bagi perusahaan yang beroperasi di Indonesia, dimana denggan adanya era globalisasi akan dapat memperluas pasar produk dari perusaahan Indonesia dan disisi lain keadaan tersebut akan memunculkan persaingan yang semakin ketat. Oleh karena itu, perusahaan harus pandai menghadapi persaingan, pengembangan usaha, menetapkan harga, mengadakan promosi dan mendistribusikan produk dengan efektif untuk mengenalkan produk watchout kepada konsumen.

Perusahaan berusaha mengenalkan produknya lewat iklan televisi, Media cetak,brosur, event bazar dan lain-lain. Tetapi dalam kondisi ekonomi dan pasar bebas membuat dampak terhadap merek Watchout karena masuknya merek- merek ternama dari luar negeri.

Kebutuhan akan sepatu yang semakin meningkat terlebih lagi bagi segmen remaja dan pria dewasa, ini merupakan segmen yang menarik dan menguntungkan. Hal ini mengakibatkan banyak perusahaan-perusahaan mulai memasuki industri sepatu.

Adapun merek-merek sepatu yang saat ini beredar di Indonesia diantaranya Fladeo, Jim Jocker, Crocodile, Watchout, Kickers dan lain-lain. Perusahaan-perusahaan sepatu tersebut baik berasal dari dalam dan luar negeri memberikan tawaran yang menarik dan beraneka ragam untuk menarik minat konsumen sehingga menimbulkan persaingan yang ketat. Mengingat hal tersebut diatas maka perusahaan dituntut untuk dapat menciptakan sesuatu yang berbeda dalam menghadapi persaingan yang ada.

Watchout sebagai salah satu merek sepatu yang diproduksi oleh PT. Binacitra Kharisma Sejati yang bertujuan memberikan kepuasan tertinggi bagi konsumen akan berusaha menetapkan strategi pemasaran yang sesuai dengan kebutuhan dan keinginan konsumen untuk membentuk citra yang positif dimata konsumen. Upaya kearah itu dilakukan melalui studi atau penelitian dengan maksut mencari sejumlah informasi 
tentang faktor - faktor yang mempengaruhi perilaku konsumen dalam pembelian suatu produk.

Masyarakat kini mulai berfikir selektif dan smart dalam memilih suatu produk, sehingga mereka akan mendapatkan kegunaan atau manfaat yang mereka cari dari sebuah produk. Bahkan, terkadang mereka tidak ragu untuk mengeluarkan biaya lebih untuk mendapatkan produk yang berkualitas, Ketatnya persaingan akan memposisikan pemasar untuk selalu mengembangkan dan merebut market share.

Salah satu untuk mencapai market share adalah merek. Merek atau brand nama, istilah, syimbol, desain, atau kombinasinya yang mengindetifikasikan suatu produk atau jasa yang dihasilkan oleh perusahaan. Salah satu peran adanya merek adalah menjembatani harapan harapan konsumen pada saat produsen menjanjikan sesuatu pada konsumen, dengan perusahaan melalui merek. Dengan banyaknya produk yang ada di pasaran akan mendorong perusahaan bersaing mendapatkan calon konsumen melalui berbagai strategi yang tepat.

Kotler dan Gary Amstrong (2008:70) Brand atau merek adalah "nama, istilah, tanda, symbol, rancangan, atau kombinasi dari semua ini yang dimaksudkan untuk mengenali produk atau jasa dari seseorang atau penjual dan untuk membedakannya dari produk pesaing".

Basu Swastha (2008:350), penjualan adalah "presentai lisan dalam suatu percakapan dengan calon pembeli atau lebih yang ditujukan untuk menciptakan penjualan. Perusahaan yang menganut konsep pemasaran, biasanya memiliki tujuan memberi kepuasan terhadap konsumen dan masyarakat lain dalam pertukarannya untuk mendapatkan laba. Hal ini berarti konsep pemasaran menganjurkan bahwa strategi perumusan pemasaran sebagai suatu rencana yang diutamakan untuk mencapai tujuan.

Penyusunan strategi pemasaran menyangkut proses interaksi antara kekuatan pemasaran di dalam perusahaan dan keadaan peluang di luar perusahaan. Strategi perusahaan merupakan pernyataan yang menunjukan usaha-usaha pemasaran pokok yang diarahkan untuk mencapai tujuan. Tujuan pemasaran menguraikan tempat yang akan dituju, strategi pemasaran menunjukan rute yang harus dilalui.

Perencanaan produk yang dihasilkan oleh perusahaan harus benar -benar sesuai dengan kebutuhan konsumen. Selain itu, produk yang dihasilkan harus mencerminkan kualitas yang baik. Hal tersebut harus sesuai dengan tujuan perusahaan yang mana produk yang dihasilkan dapat diterima dan sesuai dengan kebutuhan dan dapat memuaskan konsumen. Karena produk merupakan titik sentral dari kegiatan-kegiatan pemasaran, Keberhasilan suatu perusahaan dapat diketahui dari respon yang di tunjukan oleh konsumen.

Perkembangan persaingan antar toko sepatu ini semakin ketat dan berkembang. Hal ini perlu diperhatikan oleh perusahaan dalam melakukan penetapan harga dan memberikan produk yang berkualitas. Konsumen semakin pandai untuk memilih produk-produk yang berkualitas dengan harga yang sesuai dengan kemampuan konsumen. Pada merek sepatu Watchout merupakan salah satu merek yang menyadari persaingan diantara merek sejenis pada cabang Matahari Departmen Store. Maka brand Watchout harus lebih memperhatikan faktor yang menyebabkan adanya perubahan konsumen. Menganalisis perilaku konsumen berarti mencoba untuk memahami sebagian kehidupan manusia. Banyak faktor yang mempengaruhi seseorang untuk melakukan pembelian sepatu antara lain factor budaya, sosial, pribadi, dan psikologis. Faktor-faktor ini sangat sulit dikendalikan. Kini hal yang patut dipertanyakan adalah bagaimana citra merek (brand image) Watchout dibenak konsumen dan banyaknya faktor yang dapat mempengaruhi seorang 
konsumen dalam membuat keputusan dalam melakukan pembelian. Bagaimana citra merek dari produk Watchout dan bukan hanya karena atribut-atribut lainnya yang dimiliki oleh produk Watchout ini.

Berdasarkan uraian diatas penulis tertarik untuk melakukan penelitian apakah citra merek mampu mempengaruhi keputusan pembelian. Berdasarkan fenomena tersebut maka penulis telah mengambil judul "Pengaruh Citra Merek terhadap Keputusan Pembelian sepatu Watchout di Giant Dept Store Bintaro"

\section{B. Rumusan Masalah}

1. Bagaimana citra merek sepatu Watchout di Giant Dept Store Bintaro ?.

2. Bagaimana keputusan pembelian sepatu Watchout di Giant Dept Store Bintaro ?.

3. Adakah pengaruh antara citra merek terhadap keputusan pembelian sepatu Watchout di Giant Dept Store Bintaro ?.

\section{Tujuan Penelitian}

1. Untuk mengetahui kondisi citra merek sepatu Watchout di Giant Dept Store Bintaro.

2. Untuk mengetahui kondisi keputusan pembelian sepatu Watchout di Giant Dept Store Bintaro.

3. Untuk mengetahui pengaruh antara citra merek terhadap keputusan pembelian sepatu Watchout di Giant Dept Store Bintaro.

\section{METODE PENELITIAN}

\section{Populasi}

Populasi dalam penelitian ini berjumlah 96 responden PT. Gemilang di Jakarta

\section{Sampel}

Teknik pengambilan sampling dalam penelitian ini adalah sampel jenuh, dimana semua anggota populasi dijadikan sebagai sampel. Dengan demikian sampel dalam penelitian ini sampel yang digunakan berjumlah 96 responden.

\section{Jenis Penelitian}

Jenis penelitian yang dipakai adalah asosiatif, dimana tujuannya adalah untuk mengetahui atau mencari keterhubungan antara variabel independen terhadap variabel dependennya.

\section{Metode Analisis Data}

Dalam menganalisis data digunakan uji validitas, uji reliabilitas, analisis regresi linier sederhana, analisis koefisien korelasi, analisis koefisien determinasi dan pengujian hipotesis.

\section{HASIL PENELITIAN DAN PEMBAHASAN}

\section{Analisis Deskriptif}

Pada pengujian ini digunakan untuk mengetahui skor minimum dan maksimum skor tertinggi, ratting score dan standar deviasi dari masing-masing variabel. Adapun hasilnya sebagai berikut:

Tabel 1. Hasil Analisis Descriptive Statistics

\section{Descriptive Statistics}

\begin{tabular}{lr|r|r|r|r} 
& N & Minimum & Maximum & Mean & Std. Deviation \\
\hline Citra merek (X) & 96 & 27 & 44 & 34.01 & 3.951 \\
\hline Keputusan pembelian (Y) & 96 & 29 & 49 & 38.29 & 4.353 \\
\hline Valid N (listwise) & 96 & & & & \\
\hline
\end{tabular}


Citra merek diperoleh varians minimum sebesar 27 dan varians maximum 44 dengan ratting score sebesar 3,401 dengan standar deviasi 3,951. Skor ini termasuk pada rentang sakala 3,40 - 4,19 dengan kriteria baik atau setuju. Keputusan pembelian diperoleh varians minimum sebesar 29 dan varians maximum 49 dengan ratting score sebesar 3,829 dengan standar deviasi 4,353. Skor ini termasuk pada rentang sakala 3,40 $-4,19$ dengan kriteria baik atau setuju.

\section{Analisis Verifikatif.}

Pada analisis ini dimaksudkan untuk mengetahui pengaruh variabel independen terhadap variabel dependen. Adapun hasil pengujian sebagai berikut:

\section{a. Analisis Regresi Linier Sederhana}

Uji regresi ini dimaksudkan untuk mengetahui perubahan variabel dependen jika variabel independen mengalami perubahan. Adapun hasil pengujiannya sebagai berikut:

Tabel 2. Hasil Pengujian Regresi Linier Sederhana

\section{Coefficients $^{\mathrm{a}}$}

Unstandardized

Coefficients

\begin{tabular}{ll|l} 
Model & B & Std. Error \\
\hline $1($ Constant)
\end{tabular}

Standardized

Coefficients

Beta

Sig.

\begin{tabular}{l|r|r|r|r|r}
\hline 1 (Constant) & 8.943 & 2.418 & & 3.698 & .000 \\
\hline Citra merek $(\mathrm{X})$ & .863 & .071 & .783 & 12.216 & .000 \\
\hline
\end{tabular}

Berdasarkan hasil pengujian pada tabel di atas, diperoleh persamaan regresi $\mathrm{Y}$ $=8,943+0,863 \mathrm{X}$. Dari persamaan tersebut dijelaskan sebagai berikut:

1) Konstanta sebesar 8,943 diartikan jika citra merek tidak ada, maka telah terdapat nilai keputusan pembelian sebesar 8,943 point.

2) Koefisien regresi citra merek sebesar 0,863 , angka ini positif artinya setiap ada peningkatan citra merek sebesar 0,863 point maka keputusan pembelian juga akan mengalami peningkatan sebesar 0,863 point.

\section{b. Analisis Koefisien Korelasi}

Analisis koefisien korelasi dimaksudkan untuk mengetahui tingkat kekuatan hubungan dari variabel independen terhadap variabel dependen. Adapun hasil pengujian sebagai berikut:

Tabel 3. Hasil Pengujian Koefisien Korelasi Citra merek Terhadap Keputusan pembelian.

\section{Correlations $^{\mathrm{b}}$}

\begin{tabular}{llr|r} 
& & $\begin{array}{c}\text { Citra merek } \\
(\mathrm{X} 1)\end{array}$ & \multicolumn{1}{c}{$\begin{array}{c}\text { Keputusan } \\
\text { pembelian (Y) }\end{array}$} \\
\hline Citra merek (X) & Pearson Correlation & 1 & $.783^{* *}$ \\
\cline { 2 - 4 } & Sig. (2-tailed) & & .000 \\
\hline Keputusan pembelian (Y) & Pearson Correlation & $.783^{* *}$ & 1 \\
\cline { 2 - 4 } & Sig. (2-tailed) & .000 & \\
\hline
\end{tabular}

Berdasarkan hasil pengujian diperoleh nilai korelasi sebesar 0,783 artinya citra merek memiliki hubungan yang kuat terhadap keputusan pembelian.

\section{c. Analisis Koefisien Determinasi}

Analisis koefisien determinasi dimaksudkan untuk mengetahui besarnya persentase pengaruh dari variabel independen terhadap variabel dependen. Adapun hasil pengujian sebagai berikut: 
Tabel 4. Hasil Pengujian Koefisien Determinasi Citra merek Terhadap Keputusan pembelian.

Model Summary

\begin{tabular}{|c|c|c|c|c|}
\hline & & & & \\
\hline Model & $\mathrm{R}$ & R Square & $\begin{array}{c}\text { Adjusted R } \\
\text { Square }\end{array}$ & $\begin{array}{l}\text { Std. Error of the } \\
\text { Estimate }\end{array}$ \\
\hline 1 & $.783^{\mathrm{a}}$ & .614 & .609 & 2.720 \\
\hline
\end{tabular}

Berdasarkan hasil pengujian diperoleh nilai determinasi sebesar 0,614 artinya citra merek memiliki kontribusi pengaruh sebesar $61,4 \%$ terhadap keputusan pembelian, sedangkan sisanya sebesar 38,6\% dipengaruhi oleh faktor lain yang tidak dilakukan penelitian.

\section{d. Uji Hipotesis}

Pengujian hipotesis dengan uji t digunakan untuk mengetahui hipotesis mana yang diterima.Rumusan hipotesis: Terdapat pengaruh yang signifikan antara citra merek terhadap keputusan pembelian.

Tabel 5. Hasil Uji Hipotesis Citra merek Terhadap Keputusan pembelian.

\section{Coefficients $^{\mathrm{a}}$}

\begin{tabular}{|c|c|c|c|c|c|c|}
\hline \multirow{2}{*}{\multicolumn{2}{|c|}{ Model }} & \multicolumn{2}{|c|}{$\begin{array}{l}\text { Unstandardized } \\
\text { Coefficients }\end{array}$} & \multirow{2}{*}{$\begin{array}{c}\text { Standardized } \\
\text { Coefficients } \\
\text { Beta }\end{array}$} & \multirow[b]{2}{*}{$\mathrm{t}$} & \multirow[b]{2}{*}{ Sig. } \\
\hline & & B & Std. Error & & & \\
\hline \multirow[t]{2}{*}{1} & (Constant) & 8.943 & 2.418 & & 3.698 & .000 \\
\hline & Citra merek (X) & .863 & .071 & .783 & 12.216 & .000 \\
\hline
\end{tabular}

Berdasarkan hasil pengujian pada tabel di atas, diperoleh nilai t hitung $>\mathrm{t}$ tabel atau $(12,216>1,986)$, dengan demikian hipotesis yang diajukan bahwa terdapat pengaruh yang signifikan atara citra merek terhadap keputusan pembelian diterima.

\section{PEMBAHASAN HASIL PENELITIAN}

\section{Kondisi Jawaban Responden Variabel Citra merek}

Berdasarkan jawaban responden, variabel citra merek diperoleh ratting score sebesar 3,401 berada di rentang skala 3,40 - 4,19 dengan kriteria baik atau setuju.

\section{Kondisi Jawaban Responden Variabel Keputusan pembelian}

Berdasarkan jawaban responden, variabel keputusan pembelian diperoleh ratting score sebesar 3,829 berada di rentang skala 3,40 - 4,19 dengan kriteria baik atau setuju.

\section{Pengaruh Citra merek Terhadap Keputusan pembelian}

Citra merek berpengaruh signifikan terhadap keputusan pembelian dengan persamaan regresi $\mathrm{Y}=8,943+0,863 \mathrm{X}$, nilai korelasi sebesar 0,783 atau memiliki hubungan yang kuat dengan kontribusi pengaruh sebesar $61,4 \%$. Pengujian hipotesis diperoleh nilai t hitung $>\mathrm{t}$ tabel atau $(12,216>1,986)$. Dengan demikian hipotesis yang diajukan bahwa terdapat berpengaruh signifikan antara citra merek terhadap keputusan pembelian diterima.

\section{V.PENUTUP}

\section{Kesimpulan}

a. Variabel citra merek diperoleh ratting score sebesar 3,401 berada di rentang skala 3,40 - 4,19 dengan kriteria baik atau setuju.

b. Variabel keputusan pembelian diperoleh ratting score sebesar 3,829 berada di rentang skala 3,40 - 4,19 dengan kriteria baik atau setuju. 
c. Citra merek berpengaruh signifikan terhadap keputusan pembelian dengan persamaan regresi $\mathrm{Y}=8,943+0,863 \mathrm{X}$, nilai korelasi sebesar 0,783 atau kuat dan kontribusi pengaruh sebesar $61,4 \%$ sedangkan sisanya sebesar $38,6 \%$ dipengaruhi faktor lain. Uji hipotesis diperoleh nilai $t$ hitung $>t$ tabel atau $(12,216>1,986)$.

\section{Saran}

a. Meskipun secara keseluruhan Citra merek sepatu Watchout pada Matahari Department Store cabang Karawaci Baik, namun masih terdapat dimensi yang harus diperhatikan seperti dimensi ketepatan (accuracy) dalam hal ini sebaiknya sepatu Watchout selalu memproduksi dan menginovasi sepatu sesuai dengan kebutuhan dan mengikuti trend yang ada dipasaran.

b. Sepatu Watchout harus lebih meningkatkan keyakinan konsumen dalam keputusan pembeliannya untuk tetap memilih merek sepatu Watchout, karena di dalam variabel keputusan pembelian masih terdapat dimensi yang harus diperhatikan yaitu penyerahan jasa, untuk itu sepatu Watchout harus lebih meyakinkan kepada konsumen saat membeli sepatu Watchout dengan cara apa yang di informasikan tentang produk sepatu Watchout sesuai dengan produk dan keinginan konsumen. hal ini dilakukan agar konsumen merasa puas dan bersedia merekomendasikan ke kerabat atau teman dekat serta menjadi pembeli yang setia di masa depan.

c. Dari besarnya nilai koefisien korelasi, koefisien determinasi, dan uji signifikansi (uji-t) tersebut menunjukan bahwa masih diperlukan penelitian lebih lanjut bagi peneliti yang lain yang tidak dimasukan dalam penelitian ini, karena munculnya keputusan pembelian merupakan akibat dari banyak faktor antara lain kualitas produk, dan strategi promosi.

\section{DAFTAR PUSTAKA}

Algifari. (2015). “Analisis Regresi untuk Bisnis dan Ekonomi”. Yogyakarta: BPFE.

Arikunto, Suharsimi (2014). "Prosedur Penelitian Suatu Pendekatan Praktek". Jakarta: Rineka Cipta.

Bashu Swastha dan T. Handoko (2015) Manajemen Pemasaran Moderen, Yogyakarta: BPFE.

Erlangga, H. (2019). The Meaning, Benefit and Importance of Development Entrepreneurship in Higher Education. Asian Journal of Contemporary Education, 3(2), 105-110.

., Sifatu, W. O., Wibisono, D., Siagian, A. O., Salam, R., \& Mas'adi, M.

(2020). Pharmaceutical Business Competition in Indonesia: A Review. Systematic

Reviews in Pharmacy, 11(10), 617-623.

Freddy Rangkuti (2016) Strategi Promosi Yang Kreatif, Edisi Pertama, Cetakan Pertama Jakarta: Gramedia Pustaka Utama.

Haque, MG., Munawaroh, Sunarsi, D., (2020). Analysis of SMEs Culinary Marketing

Strategy During Covid 19 Pancemic: A Study at "Sate Bebek Cilegon" Resto in

Cilegon, Banten. International Journal of Education, Information Technology, and

Others. Vol.3. Issue 2

Imam Ghozali (2017). “Aplikasi Analisis Multivariate Dengan Program SPSS”. Edisi

Kelima. Semarang: Badan Penerbit Undip.

Istijanto (2014) "Riset Sumber Daya Manusia". Jakarta: PT. Gramedia Pustaka

Jasmani, J. (2018). Pengaruh Kualitas Produk Dan Harga Terhadap Keputusan Pembelian

Pada PT. Baja Mandiri Di Jakarta. Disrupsi Binis, 1(1).

Jasmani, J., \& Sunarsi, D. (2020). The Influence of Product Mix, Promotion Mix and 
Brand Image on Consumer Purchasing Decisions of Sari Roti Products in South Tangerang. PINISI Discretion Review, 1(1), 165-174.

Kasmad, K., Mustakim, M., \& Sunarsi, D. (2020). Increasing Community School Interest Through Service Quality, Prices and Promotion in Vocational High Schools. Journal of Educational Science and Technology (EST), 6(2).

Kharis, Ismu Fadli (2011). "Studi Mengenai Impulse Buying dalam Penjualan Online". Semarang : Skripsi Universitas Diponegoro

Khoiri, A. (2019). Meta Analysis Study: Effect of STEM (Science Technology Engineering and Mathematic) towards Achievement. Formatif: Jurnal Ilmiah Pendidikan MIPA, 9(1).

Kotler dan Amstrong (2017), Prinsip-prinsip Pemasaran. Edisi Kedua Belas”. Jilid Satu. Jakarta: Erlangga.

Maddinsyah, A., Hidayat, D., Juhaeri, J., Susanto, D., \& Sunarsi, D. (2020). Desain Formulasi Dan Implementasi Bisnis Strategik Dengan Pendekatan Business Model Canvas (BMC) Terintegrasi Kerangka Integrated Performance Management System (IPMS) Pada Koperasi Asperindo. Inovasi, 7(2), 67-76.

Mani, J. (2017). Pengaruh Persepsi Merek Dan Kualitas Pelayanan Terhadap Kepuasan Pelanggan (Studi Kasus Pada PT. Bisma Narendra Di Jakarta). Jurnal Mandiri, 1(2), 187-206.

Muis, I., Nurdin, I., Erlangga, H., \& Engkus, E. (2019). Post Disaster Social Vulnerability: Policy Analysis and Implementation in Communities in Indonesia. Journal of Critical Reviews, 6(5), 59-66.

Philip Kotler (2017) Manajemen Pemasaran, Edisi Keempat Belas, Jakarta: PT. Indeks.

Phipil Kotler dan Kevin Keller (2017) Manajemen Pemasaran, Edisi Kedua Belas, Jilid Satu, Jakarta: Erlangga.

Rao, Purba, (2012). "Measuring Consumer Perceptions Through Factor Analysis", The Asian.

Santoso, Singgih (2015). "Menguasai Statistik Multivariat". Jakarta: PT Elex Media Komputindo.

Sobarna, A., Rizal, R. M., Hambali, S., \& Sunarsi, D. (2020). Influence Make a Match Model toward Communication skills in Physical and Health Pedagogical Concept. Solid State Technology, 63(6), 1355-1363.

Sudjana (2014) "Metode Statistika", Bandung: Tarsido.

Sugiyono (2017), "Metode Penelitian Administrasi : dilengkapi dengan Metode R \& D". Bandung: Alfabeta.

Suhartanto (2014). "Metode Riset Pemasaran". Bandung: Alfabeta

Sunarsi, D. (2020). Pengaruh Bauran Pemasaran Dan Kualitas Pelayanan Terhadap Kepuasan Konsumen Pada Giant Dept Store Cabang BSD Tangerang. E-Mabis: Jurnal Ekonomi Manajemen dan Bisnis, 21(1).

Susanti, N., \& Jasmani, J. (2020). The Influence of Product Quality and Service Quality on Customer Satisfaction at Mitra 10 in Depok. Jurnal Office, 5(2), 75-84. 